\title{
Building a Sustainable Health System
}

\author{
E. Coiera', E.J.S Hovenga ${ }^{2}$ \\ 'Centre for Health Informatics, University of New South Wales, Australia \\ ${ }^{2}$ Health Informatics Research Group, Central Queensland University, Australia
}

\begin{abstract}
Summary
Objectives: To conduct a basic sustainability analysis of health systems, and explore models for conceptualising and creating sustainable organizations, based upon the experiences of the environmental sciences and organisational theory. To explore the role of information technologies in assisting health organizations become sustainable enterprises.

Methods: A review of recent literature into sustainable systems and an analysis and extension of the literature to the specific case of healthcare. Results: Many if not all health systems around the globe face dual challenges of increasing demands and diminishing resources, which are ultimately unsustainable. Four physical system conditions which are pre-requisites for sustainability of systems - that materials should not be extracted, accumulate or be depleted faster than they can be managed, and that systems should fundamentally meet human needs apply equally to healthcare. For healthcare, in addition to physical material and energy, resources include people, and data, information and knowledge. Further, healthcare is an open system that needs to be sufficiently adaptive to changes if it is to sustain. Information and communication technologies are crucial tools to enable any large and complex modern enterprise to model, measure and then manage business processes. Technologies like organisational simulation, the electronic health record, and decision support are essential tools for sustainable health services. Applied inappropriately however, IT can itself create unsustainable conditions, for example through the accumulation of legacy systems, a situation that adherence to technical standards should mitigate. Conclusions: It is crucial that our nations undertake a formal sustainability analysis of their health systems, to identify where the most pressing challenges are. In concert, there needs to be a long term process of exploring innovative designs for health services that improve the sustainability of the system as a whole, and there needs to be a will to implement the health system policies, infrastructure and services to ensure that in 20 years time we do have a healthy health system.
\end{abstract}

\section{Keywords}

Sustainable organizations, e-health, public health, health policy, government strategy, information technology, safety and quality

Geissbuhler A, Haux R, KulikowskiC, editors. IMIA Yearbook of Medical Informatics 2007. Methods Inf Med 2007; 46Supp 1: 11-8

\section{Introduction}

Sustainable organizations are ones that last. They have a clear purpose and they consistently find ways to maintain that purpose despite significant changes to the world around them. Looking forward 20 years one would hope that our health systems around the world have indeed lasted, and we might even optimistically hope that they have found a way to thrive. Yet the current challenges these health systems face, with reducing resources and increasing demands, paint a picture that suggests that our current health systems will struggle to meet their goals in 20 years time.

According to the World Business Council for Sustainable Development (WBCSD) 'nearly everyone agrees that the way we manage health today is unsustainable - it costs more than we can afford, and delivers less than we expect' [1]. Yet by 2020, the health system will have to treat proportionately more people, with more illness, higher expectations, often using more expensive technologies, and using relatively fewer tax dollars and workers. Given that commentators today are alarmed at the present strains on the health system, we have to assume that by 2020 , the healthcare system in most nations will thus either have somehow substantially transformed, or failed. If the healthcare system is to flourish in the coming setting of uncertain resources and increased demand, then it will have done so because we have explicitly designed and implemented new systems that are fundamentally sustainable. Given the likely enormity of that task, it may require nothing less than the reinvention of healthcare to create such a sustainable future [2]. The fundamental question we face therefore is - what form of health system can we envisage which is sustainable in the long run, and how do we set about building it? This paper is not a detailed introduction to sustainability theory or methods, which is significantly richer and more complex than the simple models presented here. It aims to provide a better understanding of the issues we all need to be aware of as we work towards establishing a sustainable health system, and making the best possible use of information and communication technologies. This paper borrows heavily and unapologetically from the many decades of thinking that has already gone into understanding sustainability, both from the environmental sciences and organizational theory. Its aim is to test whether these ideas and models of organizational sustainability can help us in shaping the health care system over the next 20 years.

\section{Major Trends, Challenges and Future Shaping Forces}

Sustainable organization research is an evolving discipline, but already has identified some key attributes of 'sustainability': [3]

- To survive in the long run, organizations need to have sufficient re- 
sources to meet their objectives, and any organization that presides over a degradation of their resource base, or consumes non-renewable resources, will eventually fail.

- Sustainable organizations are able to adapt to their changing environment, and do so at a rate that is faster than the rate of change in their surrounding context. An inability to cope with rapid systemic change will mean that an organization ends up being overwhelmed by the demands made of it.

The WBCSD has adopted three pillars, economic growth, ecological balance and social progress to guide sustainable activities[4]. Boxer argues that all business leaders need to promote and adopt a sustainable way of operating to achieve organisational survival [5]. He argues that a sustainable way of operation requires paying equal respect to the demands of society, the environment and financial needs. A simple model for visualising whether an organization has a sustainability problem is the 'funnel' diagram, which plots consumption of resources against resource availability (Figure 1). In real systems, a growing gap between resource supply and demand cannot be sustained for long, and corrections must be made to bring supply and demand into balance. Sustainable organizations have developed strategies that fine tune and maintain this balance in ways that avoid the need for periodic, reactionary, large and usually painful structural adjustments, or even collapse.

How might our health system stand up to such a sustainability analysis? It is clear different nations face different challenges, because of their specific local situations, but there is much to learn from the experience of other countries in the quest for sustainable health care models, both good and bad [6]. As one example, and in common with most developed nations, Australia's health system is struggling to control costs. Health care consumes $9.7 \%$ of national GDP, and is projected to increase to over $11 \%$ by 2021 . Overall inflation ran at $2.2 \%$ per year over the last decade, but health inflation averaged 3.1\% each year. Between 199394 and 2003-04, expenditure on health by Australians grew 4.6\% [7]. We are thus facing the $21^{\text {st }}$ century equivalent of the $19^{\text {th }}$ century's agrarian Malthusian challenge of working with fixed or diminishing resources to service increasing demands. For the health system, these increasing demands can be summarised into four specific challenges:

Technology driven demand challenges: Almost two thirds of the growth in health costs comes from consumer demand for new technology and treatments [8]. Consumers expect newer, usually more expensive, diagnostic procedures and medications once they become available. However there is often no economic case to adopt these innovations over more cost-effective and proven options. There is increasing evidence that poor decision-making leads to the overuse of inappropriate or wasteful health care interventions, and the under-utilisation of cost-effective interventions, with a significant national opportunity cost. One study estimates that only $21 \%$ of health technologies in use are supported by controlled research evidence [9].

Demographic driven demand challenges: Health expenditure rises sharply with advancing age, accounting for a third of health cost growth. The population aged $65+$ years is projected to double in the next 20 years. Average health expenditure in 2003 was $\$ 1,807$ for those under 65 years, $\$ 5,506$ for those 65-75 years and $\$ 15,690$ for those aged $85+$ years. People aged $65+$ years make up $13 \%$ of the population, yet account for $38 \%$ of health costs. Aus- tralians aged 65 years consult GPs more frequently, and have a higher rate of chronic conditions, consultations and prescriptions per visit [10].

Workforce Capacity and Funding Challenges: The resources needed to meet increased demands will decrease when they are needed most. As the population ages, fewer Australians will be of working age and contributing tax dollars to support government services. The health system currently faces significant workforce shortages, with average vacancy rates of $10 \%$ and the rate of increase in the health workforce is not keeping pace with the general workforce [10]. The health workforce, per capita one of the larger in the developed world, is growing by around 17,000 per year. By 2020 this will be 12,500 and for the decade 2020-2030, growth will be less than for a current single year.

Quality and Safety Challenges: Demand grows for increased quality of health services as avoidable errors are now recognised as a major cause of illness and death [11]. 17\% of hospital admissions in Australia are associated with an adverse event; $51 \%$ may be preventable, $13.7 \%$ result in permanent disability, $4.9 \%$ in death. The cost in additional bed-days alone is estimated at $5 \%$ of the annual $\$ 66$ billion health budget. Lack of information, poor communication processes, lack of standardised procedures, cognitive overload and a reliance on memory can all contribute to errors [12]. Workforce shortages exacerbate the situation as individuals have higher workloads and fewer resources.

Using these four challenges, it is clear that the trajectory of this health system, with decreasing resources and increasing demands, is fundamentally not sustainable (Figure 1). 


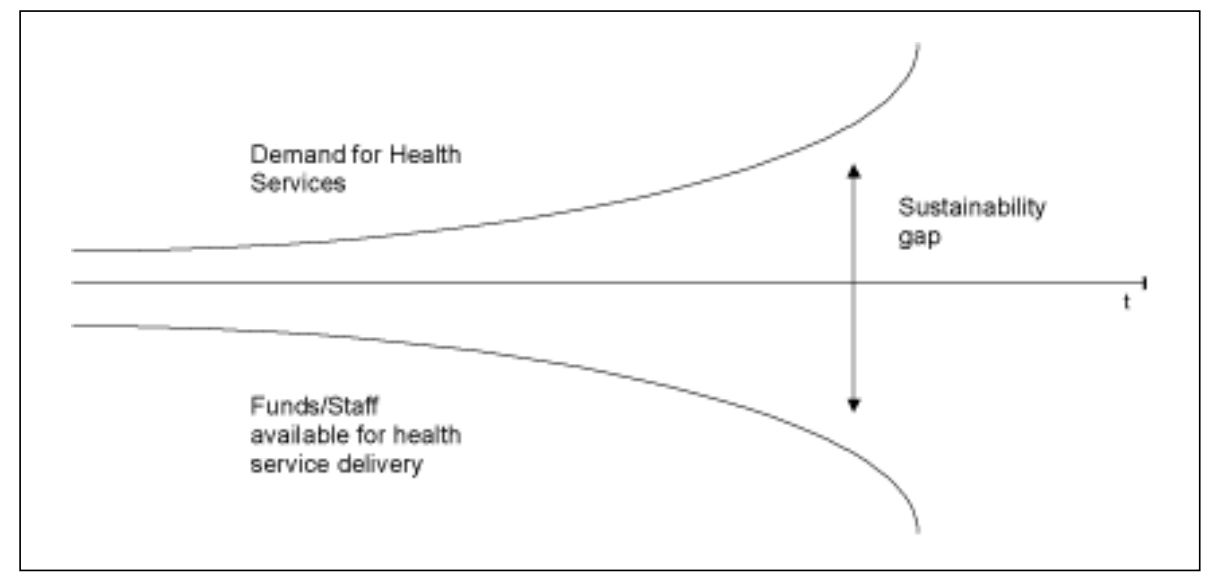

Fig. 1 The sustainability funnel - when resource availability and utilization diverge we have a sustainability gap (Source: The Natural Step). The current trajectory of many health systems is by this analysis unsustainable.

\section{The Conditions for Sustainability}

How do we find a way out of this? Sustainability experts sometimes 'backcast' from a hypothesised sustainable model of the future back to the present day, to identify the steps we need to take now to get where we want to be then. However, agreeing on many of the features of a sustainable future nirvana can be a challenge. One of the strong lessons from those working in the field of environmental sustainability is that consensus on details is often hard or impossible to achieve. Experts may quibble on just how much of a toxin in the environment is 'dangerous' or how much mobile phone radiation causes harm. However, all the experts will probably agree to a general principle, such as "the unchecked accumulation of a toxin in the environment is unsustainable". In other words, while we may not be able to agree on the concentration that's harmful, if we don't check the growth in the toxin's concentration, we can all agree that harm will occur at some time in the future.

Equally, we in healthcare might argue about how long a surgical waiting list is acceptable, how economically disadvantaged you need to be before health care is subsidised or how much of the health care spend should or will go to the private sector. However, there must be a set of principles upon which we all can agree must underpin any sustainable health system. So, before we agree on the design of our future health system, we need to agree on some sustainability 'design principles' that describe what we want that system to do. One of the leading think tanks on organisational sustainability, from an environmental perspective, is the Natural Step. Natural step thinkers have postulated four system conditions (Table 1), which they believe are fundamental principles for environmental sustain- ability, and which if adhered to, result in human enterprises that are flexible enough to respond to the unseen challenges that come to them, and are leaner and more effective as a result.

These system conditions arise out of thinking about sustainability from a material flow point of view, and seeing the issue of sustainability as one of environmental degradation. Healthcare is an enterprise that manifestly consumes physical resources, and any analysis of the sustainability of healthcare must explore how effective and efficient our enterprises are in using what we take from the world and what we put back into it. There are many case studies from the private sector which already show the enormous cost savings that can be made by transforming resource hungry and 'dirty' businesses into ones that are resource frugal and clean. Healthcare, simply on this basis alone, probably fails organisational sustainability analysis today, and would do well to focus on the way it uses physical resources, on what it wastes and fails to use effectively.

However, the healthcare system, perhaps the largest and most complex of all the organisational systems we have created, needs to be analysed in broader terms than its impact upon the physical

\section{Table 1 The Natural Step sustainability conditions}

\footnotetext{
Ecosystem functions and processes are altered when:

1. Society mines and disperses materials at a faster rate than they are re-deposited back into the Earth (examples include oil, coal and metals);

2. Society produces substances faster than they can be broken down by natural processes, if they can be broken down at all (examples of such substances include dioxins, DDT and P(Bs); and,

3. Society depletes or degrades resources at a faster rate than they are replenished (for example, over-harvesting trees or fish).

4. Further, social and economic dynamics fundamentally drive the actions that lead to ecosystem changes.

These four sustainability "conditions" articulate how, in a sustainable society, nature is not subject to systematically increasing:

1. concentrations of substances extracted from the earth's crust;

2. concentrations of substances produced by society;

3. degradation by physical means, and

4. human needs are met worldwide.
} 
environment alone. Specifically, the stocks and flows through the system are not just physical resources, but also include capital, trained staff, patients, data, clinical knowledge and so forth. An examination of the sustainability of the health system must look at all the significant system flows needed to keep the system ticking over, not just raw physical material and energy flows.

The four system conditions in Table 1 are examples of simple principles that naturally fall out of an understanding of how all physical systems work. These system conditions may be recast to help articulate which system conditions predicate healthcare sustainability, using a more general systems language:

1. Healthcare is an 'open' system. Let us first recognise that healthcare is not delivered in isolation, but that the system of healthcare sits within a broader world that provides it the human, material and informational resources it needs to function, the patients it cares for, and back into which it puts the results of its work. Consequently some sustainability challenges will only be solved outside the borders of the health system in its strictest definition. For example, cost-shifting might occur between state and federal governments, or public and private care organizations, as a result of the particular governance model chosen by a nation, and is not strictly a specific attribute of the health system. Changes in consumer lifestyles leading to increased burden of disease are also not in the direct control of the health system, although it has some ability to effect change in the broader community. Failure to understand that health care is embedded in a wider system can thus lead to over-optimisation of parts of a health care system, when the investment in systems improvement would be better spent externally. It can also lead to underoptimisation of our systems because we have made assumptions about the resources or conditions that will be available to health care, but external forces beyond our control render our systems ineffectual.

2. Resources should not be lost to the system. Training nurses, only to have them leave the system prematurely is a 'loss' to the system. Continually reducing the level of funding for a given service without making other changes to compensate is also an ultimately unsustainable strategy, whatever the cost control motivation.

3. There should not be accumulating costs in the system. Increasing numbers of chronically ill people, supported by but not 'cured' by the health system, may eventually consume all of the system's resources. Equally, accumulating new management reporting procedures in a system will eventually swamp the resources available for other purposes.

4. The system is sufficiently adaptive: The two previous principles are 'static' and we can bring in a further dynamic one that states that when there are changes to either the inputs or outputs of our system, then the system's ability to adapt to the change must be sufficiently fast so that over time we do not get accumulation or loss, for example from over or undershooting performance targets by mistimed corrective actions.

5. Care for people: A system should meet the needs of all, and by corollary not do harm unto others. People are a key resource for the delivery of health care, and a system that fails people will eventually harm itself. For example, a distressed health service which loses clinical workforce faster than they can be replenished will fail. If the quality of healthcare is poor for those on lower incomes, then the ability of the community to actively participate in the workforce is ultimately diminished, reducing the size of crucial inputs to the health system, a nation's workforce and the tax contributions and earnings of that workforce.

\section{Analysis of Options for Future Directions}

There is a growing literature on how one designs complex organizations that are sustainable, and health care organisational sustainability is beginning to gain attention [13-17], with many voices asking if the current distribution of, access to, and usage of health resources is either equitable or sustainable. Some authors have focused on the challenges of public and primary health care [18-20], with their main concern being the continued ability to deliver an appropriate level of benefits after major financial and technical donor assistance has been terminated.

Sustainability arises out of good system design. Basic to an understanding of all sustainability models is the simple idea of feedback - what goes out of the system is not lost to it, but fed back in. By feeding back 'waste' we meet our principle of not losing resources from the system. We transform 'waste' that would otherwise accumulate in and degrade the environment back into useful material. So, a company that manufactures physical products, recycles its waste because dumped waste is money lost. A company that also recycles the products it makes needs fewer primary resources to make future products. Appropriate feedback can also stabilise a system by providing information that can up or down regulate our processes based upon the state of what is happening 'upstream'. For example, feedback on current and future workforce demands can help regulate the number of clinicians being trained, or feedback on the bed status of all the local hospitals can redirect ambulances to take patients to less congested institutions. 
So, for healthcare to be sustainable, part of the solution is closing the loop between the flows into and out of the system. Health systems are complex highly connected social constructs that control: funding, access to services, workforce supply and demand, availability and cost of drugs, supplies, equipment, physical facilities and technologies, research opportunities and adoption of research results, and that shape consumer expectations and ultimately clinical outcomes. All these processes and outputs are constrained by a nation's political, legal, workplace, cultural, financial and business systems.

In Table 2, some simple examples of stocks and flows within a complex health system, sustainability condition violations or losses, and potential repair strategies are presented, to demonstrate how sustainability analysis provides us with a lens to focus on crucial aspects of the health care delivery process.

\section{The Role of Informatics and Information Technologies in Achieving Sustainable Organizations}

Many nations have now developed a Health information or e-health strategy $[21,22]$ arguing that using state of the art technologies contributes significantly to the development of a sustainable health system. Such development requires successful coordination, integration and sharing of information in a context of changing work processes, significant organizational change and forever changing political and institutional environments. The World Health Organisation (WHO) requests international collaboration, for example via the many Health Informatics standards development activities [23].

Table 2 Examples of stocks and their flows through a health system, violations of sustainability principles that may occur, and repairs that restore sustainable dynamic behaviour

\begin{tabular}{|l|l|l|}
\hline Stocks and Flows & Principle violated & System repair \\
\hline People: trained staff & $\begin{array}{l}\text { Loss of trained clinicians to system } \\
\text { because of burn out or disaffection }\end{array}$ & $\begin{array}{l}\text { 1. Minimise cause of loss: address causes of } \\
\text { burn out e.g. improved conditions } \\
\text { 2. Minimise loss to system e.g. feedback } \\
\text { leaving staff back into system via } \\
\text { retraining schemes }\end{array}$ \\
\hline People: 'wellness' & $\begin{array}{l}\text { Accruing lifestyle related diseases e.g. } \\
\text { impact of growing population obesity }\end{array}$ & $\begin{array}{l}\text { Focus on preventative rather than acute care. } \\
\text { Interventions beyond borders of care delivery eg } \\
\text { school education }\end{array}$ \\
\hline People: engaged patients & $\begin{array}{l}\text { Loss of engaged patients to alternative } \\
\text { health services }\end{array}$ & $\begin{array}{l}\text { Break down borders between allopathic and } \\
\text { alternative health services, so that all care } \\
\text { episodes are captured irrespective of location and } \\
\text { philosophy. }\end{array}$ \\
\hline Patient Information & $\begin{array}{l}\text { Loss of, or unavailability of previously } \\
\text { captured patient information, at the } \\
\text { point of care }\end{array}$ & $\begin{array}{l}\text { 1. Electronic health records 'repair' paper } \\
\text { losses. }\end{array}$ \\
& $\begin{array}{l}\text { IT standards minimise losses when new } \\
\text { systems make older ones redundant, or } \\
\text { providers use different EHR or messaging } \\
\text { approaches. }\end{array}$ \\
\hline Health service performance data & $\begin{array}{l}\text { 1. Failure to manage health services } \\
\text { without appropriate measurement tools } \\
\text { to track flows, detect losses or gains } \\
\text { across system }\end{array}$ & $\begin{array}{l}\text { Identification of crucial flows, measures for the } \\
\text { flows, and IT to monitor crucial flows eg clinical } \\
\text { information systems }\end{array}$ \\
\cline { 2 - 3 } & $\begin{array}{l}\text { 2. Failure to manage system because we } \\
\text { are not able to anticipate changes to } \\
\text { internal system performance or external } \\
\text { contextual changes }\end{array}$ & $\begin{array}{l}\text { Befter models of the system, to simulate likely } \\
\text { outcomes of changing structure, detecting threats } \\
\text { early or anticipating threats through scenario } \\
\text { planning. }\end{array}$ \\
\hline
\end{tabular}

IT can specifically assist in the quest for organizational sustainability by [24]:

- Dematerialising and digitising, reducing the footprint of the enterprise in the physical environment and transferring business to the electronic e.g. moving from paper to electronic records, cutting down on travel costs through telemedicine;

- Maximizing efficiency, by instituting tighter tracking and control of processes, to minimise wastage and error, and maximise desired outcomes e.g. better supply chain management should lead to reduced wastage and increased efficiency of the processes dependent upon supply, medication management can lead to avoidance of errors and adverse outcomes, better bed management can lead to reduced waiting times and increased patient throughput in a hospital;

- Create tools for sustainability, by making work processes, their stocks and flows, and their dependencies visible, and by creating information environments in which it becomes transparent when decisions or events are creating unsustainable system behaviours;

- Redesign products into services, moving from single point of contact, single 'product' models for health services into longer-term service arrangements. There is little scope for optimisation when encounters with a health system are broken down into small independent units, but great opportunity if there is a mechanism for looking at the 'big picture' of a patients' life. 
For example, consider the benefits that should be possible in moving from an acute intervention model where the focus is on a product like prescription of a medication or completion of a diagnostic test as the outcome, to a longer term and more complex preventative relationship with patients, integrating all the different health and lifestyle events for an individual e.g. using register/recall systems to identify when patients are due for vaccinations, screening tests, or routine physiological monitoring for chronic illness. Such services are reliant on shared and networked clinical information systems to track and trigger events in the service relationship.

As the old engineering maxim goes, 'if you can't measure it, you can't manage it'. The goal of sustainability poses a specific challenge to health care systems, because to truly be sustainable, one needs for any large organization to have a detailed understanding of its processes, an accurate means of measuring these processes dynamically, and then the means to intervene with management actions that can correct deteriorating dynamic behaviours. Information and communication technologies are thus crucial tools to enable any large and complex modern enterprise to model, measure and then manage business processes, and target sustainable practices.

\section{Modelling the Organization}

It is in the nature of health care organizations that their behaviour arises out of the complex and dynamic behaviour of many different components [25]. Causality is hard to ascribe, making it hard to understand how an individual action or intervention relates to a specific outcome. The size, uniqueness and complexity of different organizations also make it hard to generalise the experiences of any one organization to others. It is also too expensive in most cases to conduct traditional scientific analyses such as randomised controlled trials for different health service designs and components.

Computational simulation is a powerful new paradigm for understanding organisational complexity in silico [26], allowing us to develop models of health care systems, from detailed models of individual health delivery organizations through to models at the national or supranational levels. Simulations can be calibrated with the best available historic data, and validated through repeated testing under a variety of conditions, including sensitivity analyses and the use of extreme boundary conditions. They allow us to develop a rich understanding of the different information and material flows that underpin an organization, the impacts of systems at the boundaries of any given organization, and allow "whatif' explorations where we attempt to predict the likely outcomes of changes to some part of the system.

Modelling thus allows identification of organisational components that fail tests of sustainability, and also allows testing of potential remedies[27]. Importantly, the dynamic nature of simulation also provides us with some indication of how long it will take for changes to have an impact, given that in the short run, many changes to an organization will not necessarily have an impact.

Computer modelling and simulation of long run dynamic processes have underpinned the deepening understanding of many other complex systems, including global weather patterns and warming, stock markets and global financial systems, and are used in the engineering of some of the most complex mechanical artefacts developed so far including aircraft and nuclear power plants. The time for their application to health care has surely also arrived.

\section{Measuring the Organization - Assessing Health System Performance}

The performance of national health systems is known to vary widely in terms of their ability to attain key health goals. From an informatics perspective it is imperative that we are able to obtain reliable and valid data to undertake performance investigations, monitor progress and conduct trend analysis within a recognised framework. For example, we are now beginning to see the emergence of systems that enable us to track the time varying behaviour of health organizations and services. We are slowly seeing the construction of national and supranational systems to monitor the emergence and movement of new infectious diseases. Many nations have systems in place to track critical incidents such as the emergence of side-effects associated with new drugs. The importance of reducing error in health delivery has also seen the introduction of critical incident monitoring systems in many countries.

Underpinning all these systems is a basic requirement that we develop some electronic means for storing patient data. The electronic health record thus becomes a basic plank in our sustainability infrastructure, because many of the crucial data feeds needed to monitor health system behaviour come from the record, wherever it is held, or however it might be structured.

Operational effectiveness requires the ability to evaluate performance not only in terms of quality and safety of clinical care but also in terms of overall service quality, cost, dependability, flexibility and speed. Thus, sustainable practice also requires significant amounts of data 
about clinical and administrative processes, describing for example the flows of patients through a system, the status of clinical staff, the availability and utilization of resources such as drugs and beds. With increasing monitoring of process data, we are better able to see the actual dynamic behaviour of organizations, and use that data to first build meaningful models of the ways different processes interact, and then track any changes we make to the system.

Sustainability requires us to see clinical work in different ways, and measure variables not traditionally associated with biomedical informatics. For example, only recently have we realised that it is just as important to measure the communication loads on clinical staff, the number of interruptions they have, and the level of multitasking load they are under, because of the significant impact human to human communication traffic has on the quality and safety of clinical care [28]. Sustainability requires us to look widely at organisational processes, and identify bottlenecks and inefficiencies wherever they might arise, not just at the moment of clinical care.

\section{Managing the Organization}

Information technology also provides powerful tools for enactment of decisions. Biomedical informatics has a long tradition of developing decisionsupport technologies, which assist clinicians in making decisions that are aligned with the best evidence available. Better-informed decisions usually result in better clinical outcomes and reduced costs. With the merging of electronic health records and decision support systems, clinicians are increasingly in a position to make decisions based both upon the best scientific evidence, as well as patient-specific data.
For this to happen, experience repeatedly shows that health information systems need to be designed and used in a manner that integrates them with daily workflows within any organization to achieve operational effectiveness at all levels. Many now argue that optimum efficiencies can only be achieved with the widespread adoption of semantically interoperable information systems i.e. systems capable of transferring, sharing, exchanging and meaningfully using information for decision support, regulatory reporting, population surveillance, clinical practice evaluation, outcome analysis and more. In other words, interoperability should enable the reuse (and avoid the 'waste') of data for multiple, often very different purposes. One recent study of information sharing and integration in the public sector supports this view [29], identifying that the primary integration problems are semantic issues: relationships between information and decision rules, data quality, interorganisational interactions, collaboration and trust.

Health organizations need analogous technologies to manage their processes. Policies and procedures, whether they are administrative, political, or clinical, need to be evidence based. Management decision support systems in health care are challenging because there is a much smaller scientific evidence base to lean upon, and management decision making is often reactive, ad hoc, and based upon the experience of the decision makers. In such cases, tools that provide simple visualisation of data, and reveal complex and time-varying behaviours, are essential first steps in supporting decision making. Simulation also becomes a powerful tool for management in such cases, where decision makers can undertake scenario analyses under different conditions to select the best strategy, when there are no similar cases or past evidence to rely upon.
When we blend models, measurement and management systems together we get closer to closed-loop control. The degree of control automation possible is highly dependent on the existence of robust measurement technologies, clear performance parameters, and a clear understanding of the mechanisms involved. For many health organizations, such circumstances are unlikely to hold for most of their services, so we will for now have to rely on 'human in the loop' systems, such as workflow management systems where humans enact pre-agreed procedures, but have the capacity to vary decision based upon local circumstances. Sustainability thus challenges biomedical informatics to move from modelling and managing the care of individuals, to managing the totality of the organization.

Finally, it is important to recognise that information technology is not a universal panacea, and poor design and use of IT can itself lead to unsustainable practices and system behaviours. IT is only one component of any clinical service, and not the end goal itself, a maxim forgotten enough to be restated ad nauseam. Sustainable services require significant emphasis on change management and organisational process, as recent explorations into sustainable public health services is demonstrating $[13,14]$.

Further, the system principles outlined earlier indicated that uncontrolled accumulations in a system are ultimately unsustainable, and there are many examples today of such accumulations in the domain of information. Clinical records accumulate, and for chronically ill patients the size of the records being created become increasingly unwieldy, whether on paper or electronically stored. The rate of accumulation of new scientific information is a wellrecognised bottleneck to evidence-based practice, with well-recognised signifi- 
cant delays in the routine institution of practices shown to be effective in the literature. IT systems themselves can 'accumulate'. Most health services that extend over large communities and different sites accumulate different versions of clinical software, different mixes of departmental systems, and different interface solutions. Some legacy systems have been in existence for decades, and as time goes on, the expertise or resources to maintain them diminish - a classic sustainability trap. Further, the introduction of a new system will often demand that it interface with all relevant existing systems, and interfaces have the characteristic that their growth is a factorial in the number of systems communicating - another sustainability trap. It quickly becomes clear why standards, and adherence to standards, is an essential strategy to get away from a growing burden of legacy systems, and an accumulation of interfacing and maintenance tasks that have the potential to overwhelm an IT support organization over time.

\section{Conclusion}

Health care faces some significant challenges over the coming decades, based upon increasing demands and decreasing resources, making long term sustainability of the current system an essential strategic goal. We need to decide what sustainability principles we would like to see our future health system adhere to. A first principles approach to sustainability helps us conceptualise unsustainable practices and structures. This requires an agreement about the most significant sustainability indicators we need to measure. Indeed a national commitment to strict, ambitious, quantitative and well-tracked national goals is highly desirable. In- formation technology is an essential component of our response, but is no panacea.

It is crucial that our nations undertake a formal sustainability analysis of their health systems, to identify where the most pressing challenges are. In concert, there needs to be a long term process of exploring innovative designs for health services that improve the sustainability of the system as a whole, and a will to implement the health system policies, infrastructure and services that we need to ensure that in 20 years time we have a healthy health system.

\section{References}

1. World Business Council for Sustainable Development. Sustainable Health Systems.

2. Coiera E. Four rules for the reinvention of healthcare. BMJ 2004;328:1197-99.

3 . The Natural Step. The natural step framework guidebook; 2000 .

4. World Business Council for Sustainable Development. A Healthy Tomorrow? Health Systems: Facts \& Trends Affecting Business Decisions Today.

5. Boxer LJ. The sustainable way. Melbourne: Brolga Publishing; 2005.

6. Prada $\mathrm{G}$ ea. Challenging Health Care Sustainabilty - Understanding health system performance of leading countries: The Conference Board of Canada; 2004.

7. Australian Institute of Health and Welfare. Australia's Health 2006; 2006.

8. Projections of Commonwealth Health Expenditure in Australia's First Intergenerational Report. International Microsimulation Conference on Population, Ageing and Health: Modelling our Future; 2003 8-12 December, 2003; Canberra.

9. Buchan H. Gaps between best evidence and practice: causes for concern. MJA 2004;180:S48-9.

10. Australian Health Ministers Conference. National Health Workforce Strategic Framework; 2004.

11. Wilson RML, Runciman WB, Gibberd RW, Harrison BT, Newby L, Hamilton JD. The Quality in Australian Health Care Study. MJA 1995;163:458-71.

12. Australian Council for Safety and Quality in Health Care. 2nd National Report on Patient Safety; 2002.

13. Brown A, Grootjans J, Ritchie J, Townsend W, Verrinder G. Sustainabilty and Health - Supporting Global Ecological Integrity in Public Health: Alan and Unwin; 2005.

14. Shediac-Rizkallah MC, Bone LR. Planning for the sustainability of community-based health programs: conceptual frameworks and future directions for research, practice and policy Health Education Re- search 1998;13(1):87-108.

15. Olsen TI. Sustainabilty of health care: a framework for analysis. Health Policy and Planning 1998;13(3):287-95.

16. Sholzberg-Gray S. CHA's/HEAL's Perspective on Conditions for Sustainability CEO/COO Conference. Canadian College of Health Service Executives Mont Tremblant, Quebec; 2000.

17. Chen L, Evans T, Anand S, Boufford J, Brown H, Chowdhury M, et al. Human resources for health: overcoming the crisis. Lancet 2004;27:1984-90.

18. Melgaard B, Creese A, Aylward B, Olive JM, Maher C, Okwo-Bele JM, et al. Disease eradication and health systems development. MMWR Supplement 1999; Vol.48(SU01):28-35.

19. Lawn J, Cousens S, Bhutta ZA, Darmstadt GL, Martines J, Paul V, et al. Why are 4 million newborn babies dying each year? The Lancet 2004;364:399-401.

20. Braa J, Monteiro E, Sahay S. Networks of Action: Sustainable Health Information Systems Across Developing Countries. MIS Quarterly 2004;28:3.

21. Health Information Strategy Steering Committee. Health Information Strategy for New Zealand. In: Health Mo, editor; 2005.

22. Australian Government. Budget Overview - Ensuring a sustainable health system 2006.

23. World Health Organization. WHA58.28 - Resolution on eHealth.

24. Waage S, Shah R, Girshick S. Information technology and sustainabilty: enabling the future. International Journal of Corporate Sustainabilty 2003; $10(4): 2-81$ to $2-96$.

25. McDonnell G, Heffernan M, Faulkner A. Using System Dynamics to analyse Health System Performance within the WHO Framework. 22nd International Conference of the System Dynamics Society; 2004:25-29.

26. Lomi A, Larsen E, editors. Dynamics of Organizations - Computational Modeling and Organizational Theories: AAAI Press/The MIT press; 2001.

27. Kurkovski A. Educational aspects of sustaibalbe development analysis: computational models and software. Journal of Computing Sciences in Colleges 2006;21(4):24-31.

28. Coiera E. When conversation is better than computation. Journal of the American Medical Informatics Association 2000;7(3):277-86.

29. Dawes S, Cresswell A, Pardo T, Tompson F. Modeling the social and technical processes of interorganisational information integration. ACM International Conference Proceedings Series Vol.89 - Proceedings of the 2005 national conference on Digital government research 2005:289-90.

\section{Correspondence to:}

Prof. Enrico Coiera

Director

Centre for Health Informatics

University of New South Wales

UNSW 2052 NSW Australia

Tel: +61293859026

E-mail: e.coiera@unsw.edu.au 